\title{
Acute rehabilitation in critically ill children
}

\author{
Karen Choong ${ }^{\mathrm{a}, \mathrm{b}, \mathrm{c}, *}$, Nga Tran ${ }^{\mathrm{a}}$, Heather Clark $^{\mathrm{a}}$, Cynthia Cupido ${ }^{\mathrm{a}, \mathrm{b}}$ and Daniel J. Corsi ${ }^{\mathrm{d}}$ \\ ${ }^{a}$ Department of Pediatrics, McMaster University, Hamilton, ON, Canada \\ ${ }^{\mathrm{b}}$ Department of Critical Care, McMaster University, Hamilton, ON, Canada \\ ${ }^{\mathrm{c}}$ Department of Clinical Epidemiology and Biostatistics, McMaster University, Hamilton, ON, Canada \\ ${ }^{\mathrm{d}}$ Population Health Research Institute, Hamilton Health Sciences and McMaster University, Hamilton, \\ ON, Canada
}

Received 20 January 2012

Revised 6 August 2012

Accepted 15 August 2012

\begin{abstract}
Immobility increases morbidity, while early mobilization improves outcomes in adults. Rehabilitation practices in critically ill children, and the degree to which they are immobilized, are currently not well understood. The objective of this retrospective cohort study was to evaluate acute rehabilitation practices and potential barriers to mobilization in a tertiary care pediatric critical care unit (PCCU). Children aged less than $18 \mathrm{yr}$ with a greater than $24 \mathrm{~h}$ length of stay were eligible. Outcomes of interest were physical therapy (PT) practice patterns, predictors of immobility, and adverse sequelae attributable to immobility. Interventions were classified as non-mobility and mobility types of PT. Ninety-one patients were included, 46.2\% (42/91) were males. The mean age was $6.4 \pm 6.4$ yrs. Thirty-six of ninety-one $(39.6 \%)$ patients received some form of PT while in PCCU. The mean proportion of PCCU days during which PT occurred was 20\% (SD 28.8), and 3\% (3/91) of patients received PT daily. Sixteen patients (17.6\%) received exclusively non-mobility PT, 20 (22.0\%) received some form of mobility, and six $(6.6 \%)$ received both non-mobility and mobility PT. Increased severity of illness, mechanical ventilation, baseline disability and young age were identified barriers to mobilization. Immobilization is common in critically ill children. PT was often delayed until the patient was stabilized, and when performed was focused on respiratory function. Mobility PT was reserved for less sick, older, and non-mechanically ventilated patients. Future research is necessary to evaluate the significance of immobility and its impact on clinical outcomes in this population.
\end{abstract}

Keywords: Pediatric critical care, physical therapy, rehabilitation, mobilization

\section{Introduction}

Immobility increases morbidity, while early mobilization improves outcomes in adults [1]. Critically ill patients are typically confined to bed rest by virtue of the severity of their illness [2]. These patients are often viewed as "too sick" to tolerate physical therapy and their immobilization is frequently and inevitably prolonged [3]. Inactivity during critical illness has been shown to be associated with impairments in physical,

*Corresponding author: Karen Choong, McMaster Children's Hospital, 1200 Main Street West, Room 3A-78, Hamilton, Ontario, L8N 3Z5, Canada. Tel.: +1 905 5212100; Ext. 75617; Fax: +1 905 5245707; E-mail: choongk@mcmaster.ca. neuromuscular, metabolic and even cognitive function, subsequently negatively impacting on intensive care unit (ICU) outcomes and prolonged recovery following ICU discharge [1,4]. While emerging literature suggests that early mobilization is feasible, safe, well tolerated and improves outcomes in critically ill adults [5], pediatric specific data is lacking. Rehabilitation practices to minimize disability and enhance recovery in critically ill children are currently poorly understood [6,7]. Furthermore, the necessary resources to facilitate rehabilitation in this population may be inadequate [6]. Research is lacking in this field of pediatrics, and we therefore have a poor understanding of whether critically ill children are indeed "immobilized", and if they 
experience similar morbidities related to inactivity as observed in critically ill adults. The objective of this retrospective cohort study was to evaluate the acute rehabilitation practices in a tertiary care pediatric critical care unit (PCCU), and explore the potential barriers to mobilization in this population.

\section{Materials and methods}

This study was approved by the institutional research ethics board, and conducted at the McMaster Children's Hospital (Hamilton, ON). Patients aged 0-17 yrs admitted to the PCCU during a winter (February) and a summer (July) months in 2009 respectively, with a greater than $24 \mathrm{~h}$ length of stay were included. The rationale for the defined study periods was to evaluate seasonal and acuity influences on rehabilitation practices.

\subsection{Outcome measures}

The primary outcome was the proportion of patients who received acute rehabilitation while in PCCU, and the nature of rehabilitation as described by their type, timing and frequency. Rehabilitation could include the following: physical therapy (PT), occupational therapy, speech and language pathology. For the purposes of identifying patients who were mobilized, PT was classified into "non-mobility" and "mobility PT" (Appendix 1). Non-mobility PT consisted of techniques to enhance respiratory function and passive re-positioning or stretching, while mobility PT included activities focused on enhancing mobility and muscle strength (i.e. range of motion, exercises, bed mobility, transfers, pre-gait activities and ambulation). Any PT provided by physiotherapists, other healthcare professionals (e.g. nurses, respiratory therapist), or caregivers were recorded. The proportion of patients who receive early mobility PT (i.e., within $48 \mathrm{~h}$ of PCCU admission) was evaluated. Secondary outcomes of interest included barriers to mobilization PT, clinical outcomes in patients who received mobility compared to patients who received only non-mobility or no PT, and the incidence of morbidities attributable to immobility (defined in appendix 1). Adverse events attributable to PT were also recorded (e.g. tube dislodgements, falls, cardiorespiratory instability). We hypothesized a priori that the following factors may be potential barriers to mobilization:severity of illness, mechanical ventilation, young age, poor functional or cognitive ability. Severity of illness was measured using validated pediatric scoring tools (the pediatric risk of mortality (PRISM III) [8] and pediatric logistic organ dysfunction (PELOD) scores) [9], and the pediatric cerebral performance category (PCPC) and the pediatric overall performance category (POPC) scores on admission were used to quantify cognitive and functional ability of each patient at baseline, and on PCCU discharge [10].

\subsection{Statistical analysis}

Based on the institutional admission rates, we estimated that we would obtain a sample of approximately 100 patients during the study period, which would provide an adequate sample to evaluate descriptive patterns and explore barriers to mobilization PT using univariate logistic regression analyses. Descriptive summaries were used to present baseline patient demographics. Categorical data were reported as percentages and continuous data as a mean (standard deviation [SD]) or median (interquartile range $[\mathrm{IQR}]$ ), depending on the distribution. Univariate comparisons for categorical data were computed using the chi-squared or Fisher's exact test if the expected values in any single cell were less than 5. Continuous data were compared using t-test or nonparametric Wilcoxon rank test if data were skewed. Analysis of variance was performed to compare the mean age, and severity of illness scores (PRISM III and PELOD scores) across patients grouped according to type of PT received (non-mobility PT, mobility FPT, or no-PT). Time to physiotherapist assessment is presented as median number of days since PICU admission and severity of illness (PRISM III score) using linear regression. A multinomial regression analysis was used to explore the barriers to mobilization. We hypothesized that barriers to mobilization may also be predictors of not receiving any PT, and therefore a multinomial logistic regression analysis was conducted to evaluate the probability of mobilization and no PT, respectively. We included the following potential predictors in the model: PRISM III score, PELOD score, and presence of mechanical ventilation, vasoactive or sedative infusions, corticosteroids, or neuromuscular blockade use at any time during the PICU admission. Results were reported as odds ratios (OR) with 95\% confidence intervals (CI) for binary outcomes and associated $P$ values. The criterion for statistical significance was set at alpha $=0.05$. All statistical analyses were completed using Stata software version 11.2 (www. stata.com). 


\section{Results}

A total of 91 children were admitted to PCCU during the study period (33 in February, and 58 in July) that fulfilled eligibility criteria and were included in the analyses (Table 1). Forty-two patients (46\%) were males, and the mean age was $6.4 \pm 6.4$ yrs. The baseline demographics for the patients are presented on Table 1. Sixtyfive $(71.4 \%)$ patients were assessed to have normal baseline PCPC scores, and $62(68.1 \%)$ patients were normal, or had minor physical disabilities as measured by POPC score.

\subsection{Rehabilitation practice patterns}

Physician orders requesting physiotherapy consultations were present in $31.9 \%$ (21/91) of patients (Table 2). The median time from PCCU admission to a written PT consult request was 2 days (IQR 5). Seven (7.7\%) patients received PT without a written physician's order. The commonest type of therapy requested by MDs was "chest-physio" (34.5\%). Thirty-nine percent (36/91) received some form of PT during their PCCU stay. Of these patients, $17.6 \%$ (16/91) received exclusively nonmobility PT, $22.0 \%$ (20/91) received some form of

Table 1

Baseline demographics and rehabilitation services

\begin{tabular}{|c|c|}
\hline Variable & $\begin{array}{l}\text { Number of patients } \\
(\mathrm{n}=91) \\
\mathrm{n}(\%)\end{array}$ \\
\hline Age (years); mean $\pm \mathrm{SD}$ & $6.4 \pm 6.4$ \\
\hline Gender; males & $42(46.2)$ \\
\hline \multicolumn{2}{|l|}{ Month of admission } \\
\hline February & $33(36.3)$ \\
\hline July & $58(63.7)$ \\
\hline \multicolumn{2}{|l|}{ Severity of illness and functional measures; mean \pm standard deviation } \\
\hline Pediatric Risk of Mortality III score* on admission mean \pm SD & $4.2 \pm 5.2$ \\
\hline Pediatric Logistic Organ Dysfunction score ${ }^{* *}$ on admission & $7.7 \pm 9.1$ \\
\hline Reason for admission & $\mathrm{n}(\%)$ \\
\hline Respiratory tract infection & $26(28.6)$ \\
\hline Sepsis & $5(5.5)$ \\
\hline Septic shock & $6(6.6)$ \\
\hline Trauma & $9(9.9)$ \\
\hline Surgical & $30(33.0)$ \\
\hline Metabolic disorder & $4(4.4)$ \\
\hline Neurological disorder & $4(4.4)$ \\
\hline Cardiovascular & $3(3.3)$ \\
\hline Poisoning/overdose & $4(4.4)$ \\
\hline Pediatric cerebral performance category $* * *$ score on admission; mean $\pm \mathrm{SD}$ & $1.3 \pm 0.8$ \\
\hline \multicolumn{2}{|l|}{ Distribution of pediatric cerebral performance category scores } \\
\hline Normal & $65(71.4)$ \\
\hline Mild disability & $7(7.7)$ \\
\hline Moderate disability & $10(11.0)$ \\
\hline Severe disability & $9(9.9)$ \\
\hline Pediatric overall performance category score on admission; mean $\pm \mathrm{SD}$ & $2.2 \pm 1.0$ \\
\hline \multicolumn{2}{|l|}{ Distribution of pediatric overall performance category scores } \\
\hline Good overall performance & $46(50.5)$ \\
\hline Mild overall disability & $16(17.6)$ \\
\hline Moderate overall disability & $16(17.6)$ \\
\hline Severe overall disability & $13(14.3)$ \\
\hline Mechanical ventilation & $44(48.4)$ \\
\hline Invasive & $35(38.5)$ \\
\hline Invasive and non-invasive & $11(12.1)$ \\
\hline Non-invasive only & $9(9.9)$ \\
\hline
\end{tabular}

*Assessment range 0-71, with higher scores indicating a greater risk of death [8].

**Assessment range 0-71, with higher scores indicating more severe organ dysfunction [9].

***Range for pediatric overall performance category and pediatric cerebral performance category scores are 1-7 from 1 = Normal,

increasing scores indicating increasing disability, $6=$ Brain death or $7=$ Cardio respiratory death $[10]$. 
Table 2

Rehabilitation practices

\begin{tabular}{|c|c|}
\hline Variable & $\begin{array}{l}\text { Number of patients } \\
\qquad(\mathrm{n}=91) \\
\mathrm{n}(\%)\end{array}$ \\
\hline \multicolumn{2}{|l|}{ Medical doctor orders } \\
\hline Written medical doctor order/consult request for physical therapy medical doctor & $29(31.9)$ \\
\hline \multicolumn{2}{|l|}{ Specific type of physical therapy consult requested; n (\% of 29) } \\
\hline Not specified & $14(48.3)$ \\
\hline Respiratory physical therapy & $10(34.5)$ \\
\hline Passive re-positioning/range of motion & $3(10.3)$ \\
\hline Mobilization & $2(6.9)$ \\
\hline \multicolumn{2}{|l|}{ Other rehab therapy/consultation requested by medical doctor } \\
\hline Occupational therapy & $11(12.1)$ \\
\hline Feeding and swallowing & $3(3.3)$ \\
\hline Speech and language & $2(2.2)$ \\
\hline Patients who received physical therapy during pediatric critical care unit admission & $36(39.6)$ \\
\hline \multicolumn{2}{|l|}{$\begin{array}{l}\text { Type of physical therapy* }\end{array}$} \\
\hline Non-mobility physical therapy & $22(24.1)$ \\
\hline Respiratory physiotherapy & $20(22.0)$ \\
\hline Passive re-positioning or stretching & $7(7.7)$ \\
\hline Mobility physical therapy & $20(22.0)$ \\
\hline Exercises & $10(11.0)$ \\
\hline Bed mobility & $2(2.2)$ \\
\hline Transfers & $4(4.4)$ \\
\hline Ambulation & $8(8.8)$ \\
\hline $\begin{array}{l}\text { Time to first physical therapy (days; } n=36 \text { ), adjusted for severity of illness; median } \\
\text { (interquartile range) }\end{array}$ & $3.2(1.5)$ \\
\hline Time to first non-mobility physical therapy & $4.8(2.5)$ \\
\hline Time to first mobility physical therapy & $1.5(1.2)$ \\
\hline Duration of physical therapy (days); median (interquartile range) & $2.5(3.5)$ \\
\hline \multicolumn{2}{|l|}{ Physical therapy delivered by (\%, $\mathrm{n}=110$ physical therapy sessions) } \\
\hline Physiotherapist & $95(86.4)$ \\
\hline Registered nurse & $11(10.0)$ \\
\hline Respiratory therapist & $2(1.8)$ \\
\hline Occupational therapist & $2(1.8)$ \\
\hline Family member & $1(0.9)$ \\
\hline
\end{tabular}

*Patients may have received more than one type of physical therapy during pediatric critical care unit admission; six patients received a combination of non-mobility and mobility physical therapy during pediatric critical care unit admission.

mobility PT, 6.6\% (6/91) received a combination of nonmobility and mobility PT, while $60.4 \%$ (55/91) did not receive any PT. The commonest form of PT performed was respiratory PT $(22.0 \%$; 20/91). Fourteen of 91 (15.1\%) patients received early mobilization. The mean proportion of PCCU days during which PT was performed for all patients was 20\% (SD 28.8). Three patients (3.3\%) received PT daily while in PCCU. PT was performed by a physiotherapist in $86.4 \%$ of occasions. The median time to the first physiotherapist assessment was 2.0 days (IQR 2.0) overall, and 3.2 (IQR 1.5) days when adjusted for severity of illness. Five of the 36 (14\%) patients had delays to PT of $1 \mathrm{wk}$ or longer. The median duration of PT (of any form) was 2.5 (IQR 3.5) days; non-mobility PT was applied for a longer duration (median of 4.0, IQR 11.5 days), than mobility PT (median 2.0, IQR 2.0 days $),(P=0.03)$. The median time to other rehabilitation, consults while in PCCU were as follows: occupational therapy (7 days), feeding and swallowing (4 days), and speech and language (27 days).

\subsection{Patient characteristics}

Comparisons of clinical outcomes according to whether the patient received mobility, non-mobility or no-PT are presented on Table 3. There was a statistically significant difference in the age, severity of illness (PRISM and PELOD scores), duration of mechanical ventilation, and length of PCCU stay between the three groups. Patients who received non-mobility PT only were significantly sicker than those who received mobility PT $(P=0.004$ for PRISM; $P<0.001$ for PELOD scores respectively). Non-mobility PT patients required 
Table 3

Comparisons of baseline characteristics and outcomes according to type of physical therapy received

\begin{tabular}{|c|c|c|c|c|}
\hline Variables & $\begin{array}{l}\text { No physical } \\
\text { therapy }(\mathrm{n}=55)\end{array}$ & $\begin{array}{l}\text { Non-mobility physical } \\
\text { therapy }(\mathrm{n}=16)\end{array}$ & $\begin{array}{l}\text { Mobility physical } \\
\text { therapy }(\mathrm{n}=20)\end{array}$ & $\mathrm{p}$ value \\
\hline Age (years); mean $\pm \mathrm{SD}^{*}$ & $5.2 \pm 6.4$ & $5.4 \pm 5.0$ & $10.7 \pm 5.4$ & 0.003 \\
\hline Pediatric Risk of Mortality III score; mean \pm SD* & $3.0 \pm 4.0$ & $9.3 \pm 7.7$ & $3.5 \pm 3.0$ & $<0.0001$ \\
\hline $\begin{array}{l}\text { Pediatric Logistic Organ Dysfunction score (Day } 1) \\
\text { mean } \pm \mathrm{SD}^{*}\end{array}$ & $4.7 \pm 7.0$ & $18.3 \pm 9.8$ & $7.7 \pm 7.6$ & $<0.0001$ \\
\hline $\begin{array}{l}\text { Duration of mechanical ventilation }{ }^{\dagger} ; \text { median days } \\
\quad \text { (interquartile range) })^{* *}\end{array}$ & $3.0(8.0)$ & $8.0(13.0)$ & $1.0(8.0)$ & 0.025 \\
\hline $\begin{array}{l}\text { Length of stay in pediatric critical care unit, days; } \\
\text { median (interquartile range)** }\end{array}$ & $2.0(2.0)$ & $11.5(18.5)$ & $4.0(6.0)$ & $<0.0001$ \\
\hline $\begin{array}{l}\text { Duration of vasoactive infusions }{ }^{\ddagger} \text {; median days } \\
\text { (interquartile range)** }\end{array}$ & $5.0(9.5)$ & $13.0(31.0)$ & $1.0(0.0)$ & 0.086 \\
\hline Pediatric critical care unit mortality; $\mathrm{n}(\%)^{* * *}$ & $1(1.8)$ & $2(12.5)$ & $0(0.0)$ & 0.07 \\
\hline Decubitous ulcers; $\mathrm{n}(\%)^{* * *}$ & $2(3.64)$ & $4(25.0)$ & $0(0.0)$ & 0.004 \\
\hline
\end{tabular}

Pediatric Risk of Mortality III score, assessment range 0-71, with higher scores indicating a greater risk of death [8]; Pediatric Logistic Organ Dysfunction score, assessment range 0-71, with higher scores indicating more severe organ dysfunction [9].

$* \mathrm{P}$ values derived from analysis of variance.

**P values derived from Kruskal-Wallis.

$* * * \mathrm{P}$ values derived from Chi-squared test with d.f. $=2$

${ }^{\dagger}$ Number of patients mechanically ventilated; no physical therapy $\mathrm{n}=20$, non-mobility physical therapy $\mathrm{n}=15$; mobility physical therapy $\mathrm{n}=9$

${ }^{\ddagger}$ Number of patients who received vasoactive infusions: no physical therapy $n=4$, non-mobility physical therapy $n=6$, mobility physical therapy $n=2$.

longer durations of vasoactive infusion $(P=0.043)$ and mechanical ventilation $(P=0.015)$, when compared to patients who received mobility PT. The length of PCCU stay was also significantly greater amongst those who received non-mobility $\mathrm{PT}$ only, when compared to those who received mobility PT $(P=0.008)$, or no-PT respectively $(P<0.001)$. There was no statistical difference in the mortality rates between the groups $(P=0.07)$. Six $(6.6 \%)$ of the 91 patients developed decubitus ulcers, two from the no-PT group and four from the nonmobility PT group, compared to none of the mobility PT group $(P=0.004)$. Two $(2.2 \%)$ patients experienced sedative withdrawal and one patient $(1.1 \%)$ developed new onset of neuromuscular weakness during their PCCU admission; both patients were from the nonmobility PT group $(P=0.1)$. There were no reported adverse events attributable to PT of either category.

Figure 1 displays the differences in type and timing of PT based on the presence of invasive mechanically ventilation. Thirty-six (39.6\%) of the 91 patients were mechanically ventilated, $21(58.3 \%)$ of whom received PT while in PCCU. Ten of the 21 (47.6\%) patients received PT while they were still intubated. The commonest form of rehabilitation in these patients was respiratory PT ( $90 \%$ of cases). A total of nine of the $35(25.7 \%)$ mechanically ventilated patients received mobility PT; the majority of whom (eight of nine; $88.9 \%$ ) were mobilized only after they were extubated, and one patient $(11.1 \%)$ was mobilized while still intubated. Amongst the 47 PCCU patients who were not mechanically ventilated, $12(25.5 \%)$ received PT during their PCCU stay; of whom 1/12 (8.3\%) received non-mobility PT and 11/12 (91.7\%) received mobility PT, respectively. The time to PT in patients who were not mechanically ventilated was significantly earlier than those who were (mean 1.6 days vs. 5.0 days, mean difference 3.4 days, 95\% CI: $0.08-6.8$ days, $P=0.01)$.

\subsection{Barriers to mobilization}

Multinomial regression analyses revealed that patients with baseline moderate to severe functional and cognitive disability (according to POPC and PCPC scores) were statistically less likely to receive mobilization PT (Table 4). Increased severity of illness was associated with a reduced likelihood of mobility PT (OR and 95\% CI for PRISM III score, 0.83 [0.71-0.97], and PELOD score, 0.89 [0.82-0.97]). Similarly, mechanical ventilation (OR $0.05 ; 95 \%$ CI $0.01-0.50)$, corticosteroid use (OR 0.08; 95\% CI 0.02-0.41) and neuromuscular blockade (OR 0.19; 95\% CI 0.04-0.85) were associated with a reduced likelihood of being mobilized. Older age was associated with a greater likelihood of mobilization (OR 1.14, 95\% CI 1.02-1.38). There was no statistical difference in the frequency or type of PT administered in the summer versus winter months, respectively 


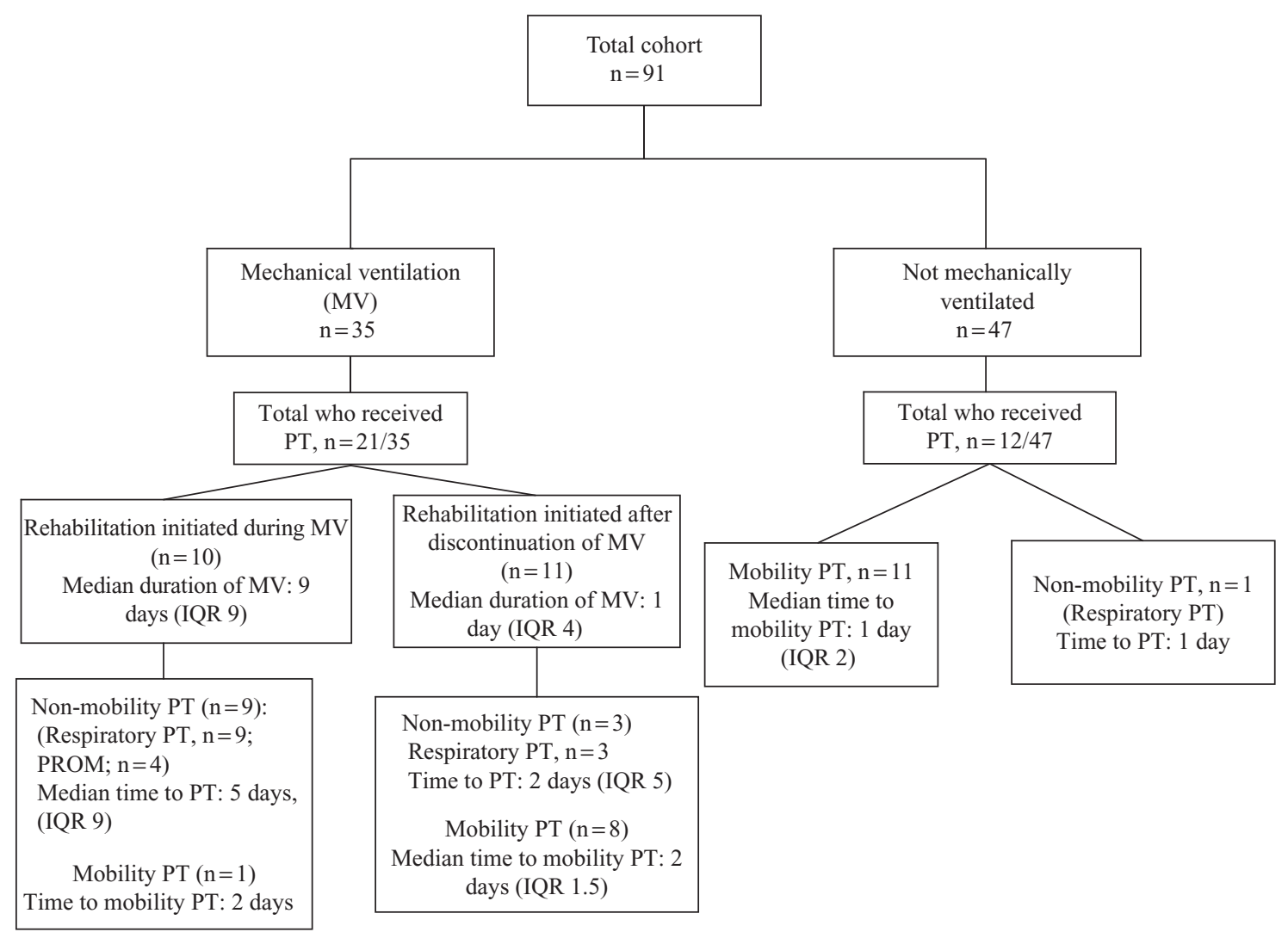

Legend: MV: mechanical ventilation; PT: physical therapy; PROM: passive range of motion; IQR: inter-quartile range

Fig. 1. Physical therapy practices in mechanically ventilated and non-ventilated patients.

Table 4

Barriers to physical therapy (physical therapy) and mobilization*

\begin{tabular}{|c|c|c|c|c|}
\hline \multirow[t]{2}{*}{ Variable } & \multicolumn{2}{|c|}{ Likelihood of mobilization } & \multicolumn{2}{|c|}{ Likelihood of physical therapy } \\
\hline & Odds ratio $(95 \% \mathrm{CI})$ & $\mathrm{P}$ value & Odds ratio $(95 \% \mathrm{CI})$ & $\mathrm{P}$ value \\
\hline Age (years) $* *$ & $1.14(1.02-1.38)$ & 0.02 & $0.99(0.90-1.09)$ & 0.90 \\
\hline July admission (vs. february) & $2.33(0.57-9.60)$ & 0.24 & $1.26(0.41-3.89)$ & 0.69 \\
\hline Pediatric risk of mortality III score $* * *$ & $0.83(0.71-0.97)$ & 0.02 & $0.80(0.70-0.92)$ & $<0.01$ \\
\hline Pediatric logistic organ dysfunction score $* * *$ & $0.89(0.82-0.97)$ & $<0.01$ & $0.84(0.78-0.91)$ & $<0.01$ \\
\hline Pediatric cerebral performance category score ${ }^{* * *}$ & $0.44(0.22-0.87)$ & 0.02 & $0.52(0.32-0.85)$ & 0.01 \\
\hline Pediatric overall performance category score $* * *$ & $0.42(0.22-0.79)$ & 0.01 & $0.54(0.33-0.89)$ & 0.02 \\
\hline Mechanical ventilation & $0.05(0.01-0.50)$ & 0.01 & $0.04(0.00-0.31)$ & $<0.01$ \\
\hline Vasoactive infusions & $0.19(0.03-1.10)$ & 0.06 & $0.13(0.03-0.55)$ & 0.01 \\
\hline Sedative infusions & $0.33(0.08-1.39)$ & 0.13 & $0.08(0.02-0.31)$ & $<0.01$ \\
\hline Systemic corticosteroids & $0.08(0.02-0.41)$ & $<0.01$ & $0.13(0.04-0.44)$ & $<0.01$ \\
\hline Neuromuscular blockade & $0.19(0.04-0.85)$ & 0.03 & $0.15(0.04-0.51)$ & $<0.01$ \\
\hline
\end{tabular}

*Multinomial regression analysis was used to evaluate barriers to physical therapy and mobilization in patients who did not receive any physical therapy, non-mobility physical therapy only, and mobilization physical therapy. The outcome was specified as a categorical variable with the following categories: non-mobility physical therapy (reference category), mobility physical therapy, and no physical therapy.

**Odds for increasing years of age.

***Odds for increasing Pediatric Risk of Mortality III and Pediatric Logistic Organ Dysfunction scores. Pediatric overall performance category; pediatric cerebral performance category (assessment range for pediatric overall performance category and pediatric cerebral performance category scores are $1-7$, where $1=$ Normal, increasing scores indicate increasing disability, $6=$ Brain death or 7 = Cardiorespiratory death) [10]; Pediatric Risk of Mortality III score, assessment range $0-71$, with higher scores indicating a greater risk of death [8]; Pediatric logistic organ dysfunction score, assessment range 0-71, with higher scores indicating more severe organ dysfunction [9]. 
(OR 2.33, 95\% CI: 0.57-9.60). We found that similar predictors (i.e. higher PRISM-III and PELOD scores, baseline patient functional and cognitive disability, mechanical ventilation, and corticosteroid use) were also associated with a lower likelihood of receiving any PT (Table 4).

\section{Discussion}

Hippocrates suggested that "in every movement of the body, whenever one begins to endure pain, it will be relieved by rest" [11]. Bed rest therefore became valued as an integral part of the management of acute illness. The care of critically ill patients is typically focused on efforts to restore acute organ function and reverse cardiorespiratory instability. As a result, inactivity and delayed mobilization is common in critical care units, with very little attention paid to the preservation of neuromuscular structure and function. Critical illness itself can result in accelerated muscle loss greater than the effect of immobilization alone [12]. There has been increased awareness recently that immobility is an important contributing factor to the pathogenesis of neuromuscular weakness, which in turn adversely affects clinically important patient outcomes and recovery following critical illness [1,13,14]. Emerging adult data suggests that early mobilization may be effective in reducing ventilator-days, ICU and hospital stay, duration of delirium and enhances return to independent functional status at hospital discharge $[5,15,16]$. Early physical rehabilitation has therefore been advocated to improve recovery from critical illness and functional recovery after ICU discharge. In contrast to the wealth of adult studies, there is a paucity of research on acute rehabilitation interventions in critically ill children.

This single center study reveals several interesting findings. Firstly, 39\% of all PCCU admissions with a length of stay greater than $24 \mathrm{~h}$ received PT while in PCCU, with therapy occurring on $28 \%$ of all PCCU days. While this may be considered low, it appears higher in comparison to previous adult studies where $12.5-27 \%$ of ICU survivors receive PT under "usual care" circumstances while still in ICU, and therapy occurs on only $6 \%$ of all ICU days [4,17-19]. Secondly, the type of PT applied varies according to the severity of illness of the patient. While the majority of patients who received PT were intubated and ventilated, these patients received primarily non-mobility interventions. Mobilization PT appears to be reserved for those patients who are less sick or whose critical illness has resolved or stabilized, and for patients that are older. The commonest form of PT overall was respiratory PT. This type of PT was delayed for a median of 4.8 days, when the patient is presumably more stable. Much research has been directed towards respiratory PT in critically ill patients, with the objectives of improving or preventing respiratory insufficiency and pulmonary complications. However, the evidence for respiratory PT in critically ill patients is inconsistent [20]. Although respiratory PT is the commonest form of PT provided in adult and pediatric ICUs [21,22], it has not been demonstrated to facilitate weaning from mechanical ventilation, shorten ICU or hospital stay nor decrease morbidity and mortality.

In contrast, early mobilization PT focused on maintaining or enhancing muscle strength, range of motion and physical function has been shown to be feasible and safe in mechanically ventilated, critically ill patients, and improves ICU related and post-ICU outcomes without increasing costs in the adult population $[5,17,23,24]$. While there is convincing evidence that this strategy of acute rehabilitation can benefit the sickest critically ill adults, mobilization in this pediatric study appears to be reserved for children who are the least sick, not mechanically ventilated, and older. Identified barriers to mobilization were young age, high severity of illness scores, increasing functional and cognitive disability, the presence of mechanical ventilation, sedative and vasoactive infusions. With the exception of age, these factors were also identified barriers to receiving any PT. Regression analyses suggested that the sickest patients were more likely to receive non-mobility interventions. It also supports our hypothesis that those who are the least sick, were most likely to mobilize early, or not receive any PT at all. Only one patient who was mechanically ventilated was mobilized while still intubated. Mobilization occurred only after extubation in the remainder of patients. Because this group of patients were less sick and had short durations of ventilator support (median of 1 day), their time to mobilization actually occurred early (median 2 days). The older age in this group of patients is likely explained by the cognitive and functional ability of these patients to ambulate and cooperate with mobilization exercises, in contrast to the non-mobility group. These important factors speak to the challenges to implementing early mobilization in pediatrics. In contrast to adults, young critically ill children and those who have underlying disabilities are often unable to understand or comply with this 
intervention. This population may constitute up to $67 \%$ of PCCU admissions [22]. The baseline POPC and PCPC scores in our study cohort are comparable to published literature [25]. Children are also more likely to be heavily sedated during their critical illness and during invasive support for the purposes of maintaining hemodynamic and metabolic stability and presumably patient safety, and there is a lack of agreement with respect to sedation regimens in pediatrics and how best to "awaken" these patients daily [26,27]. It is unclear therefore, whether daily interruption of sedation, which is integral to early mobilization, is feasible, and whether children who are at highest risk of morbidity, mortality and subsequently PCCU acquired weakness, could benefit from this intervention. We found an incidence of PCCU acquired weakness in this retrospective study of $1.1 \%$, which is similar to that reported in a previous prospective study [6]. While the true incidence of PCCU acquired weakness remains unclear in this population these data suggest that it may be much lower than that reported in the adults [28], or that it is substantially under-recognized. There was also evidence of other important morbidities associated with immobility; $6.6 \%$ of patients developed decubitus ulcers, all of whom were from the non-mobility or no PT group.

An additional important potential barrier to mobilization may be related to the knowledge and perceptions of the caregivers. Only $32 \%$ of PCCU patients had a formal request for a physical therapist assessment, and the majority of these consults did not specify what was requested. The most common request amongst those that were specified, were for respiratory PT. There may be a lack of awareness on the part of physicians of the importance of engaging physiotherapists early during the management of critical illness, avoiding inactivity during critical illness, the forms of therapies that may be beneficial beyond respiratory PT, and the potential importance of mobilization. We acknowledge the following limitations to this study: there are biases inherent to retrospective data collection. The quality of the data collected is therefore influenced by the quality of the documentation, and the incidences of immobility associated sequelae are likely underestimated. Barriers to mobilization PT were assessed only in the group who received PT. Therefore, we are unable to draw any firm conclusions on the group that did not receive PT. These patients represent a heterogeneous group, and it is likely that within them there were patients who were assessed to be "too well", as well as patients who were deemed "too sick" to receive PT. Inferences have been made based on the evaluation of these practice patterns amongst those who received PT. However, true barriers and other influences on practice such as knowledge and perceptions, are better captured by prospective and survey study designs. Nevertheless, this is one of the first studies to our knowledge to evaluate acute rehabilitation practices within a PCCU, and provides important and relevant information specific to pediatrics. This study demonstrates that at least in this single Canadian center, rehabilitation practices differ in comparison to adult ICU data from the United States [4]. Furthermore, it rationalizes future research in this area, and highlights important aspects unique to pediatrics that should be considered in the design of future prospective, interventional studies of acute rehabilitation in critically ill children. There is clear evidence of marked diversity of rehabilitation practices in the adult ICU setting [19]. The results of this study are clearly not generalizable, and rehabilitation interventions in other PCCUs should be evaluated to further inform us of variations in pediatric specific practices and resource utilization. It is likely that practices are similarly diverse for critically ill children: the resources for rehabilitation amongst PCCUs appear to be variable [22], the knowledge and perceptions of the role of acute rehabilitation in PCCUs is unknown, there are currently no guidelines for physical therapy in pediatric patients with critical illness [3], and subsequently there are a paucity of children's hospitals with established criteria or protocols for physical therapy [21]. As survival rates in children improve and the utilization of pediatric critical care unit (PCCU) services continues to grow [22], it becomes increasingly important for clinicians to focus on outcomes beyond survival, to the prevention and management of potential complications of critical illness and critical care. Critical illness negatively impacts neurocognitive and functional recovery [22,29], and can result in substantial physical sequelae in children [30]. Therefore, the feasibility, safety and efficacy of acute rehabilitation and early mobilization within the PCCU setting need to be evaluated.

In conclusion, the results of this study demonstrate that immobilization is common in the PCCU particularly amongst the sickest and youngest children who may in fact be at highest risk of morbidity. The critically ill pediatric population is clearly unique in terms of their needs, nature of illness, and diversity in functional and cognitive ability, which underscores the numerous 
challenges when considering acute rehabilitation in this setting. Prospective, epidemiological data quantifying the magnitude of the problem, evaluating PCCU and post PCCU outcomes, and describing current practice patterns is much needed. The types of interventions that can be applied to encourage early mobilization would need to be tailored to the broad age range and abilities of these patients; and finally, it remains to be determined if early rehabilitation is safe, feasible and ultimately beneficial in critically ill children.

\section{Acknowledgements}

We would like to thank Dr. Shikha Gupta for her assistance with data abstraction for this study.

Appendix 1

Definitions

\begin{tabular}{|c|c|}
\hline Non-mobility physical therapy & Definition \\
\hline Respiratory & $\begin{array}{l}\text { Physical methods to improve alveolar ventilation and perfusion matching, breathing mechanics and } \\
\text { airway secretions clearance. May include manual percussion and vibrations, postural drainage, } \\
\text { breathing exercises, cough assist, and manual hyperinflation. }\end{array}$ \\
\hline $\begin{array}{l}\text { Passive range of motion or } \\
\text { re-positioning }\end{array}$ & $\begin{array}{l}\text { Includes passive re-positioning of patient, or passive stretching of their limbs and joints. Passive = } \\
\text { patient does not voluntarily participate in the activity }\end{array}$ \\
\hline Mobility physical therapy & Definition \\
\hline Exercises & $\begin{array}{l}\text { Muscle strengthening exercises with therapist. This may be described as 'active' or 'active-assisted' } \\
\text { exercises. "Active" infers patient participation, no matter how little. This may include exercises and } \\
\text { stretches that are taught to patient to do independently, and/or an exercise device (e.g. bedside cycle } \\
\text { ergometer). Includes neurodevelopmental play: (i.e. play activities to facilitate fine and gross motor } \\
\text { development for infants and developmentally delayed children. }\end{array}$ \\
\hline Bed mobility & $\begin{array}{l}\text { Activities done while patient is recumbent - but requires active participation of the patient; e.g. active or } \\
\text { active-assisted repositioning in bed; rolling from side to side; and bridging (i.e. pelvic or hip lifts) }\end{array}$ \\
\hline Transfers & $\begin{array}{l}\text { Patient actively transfers from one surface to the other e.g. from bed to chair/commode, sitting or } \\
\text { dangling on edge of bed, unsupported sitting or sitting with trunk control, assisting from a sitting to a } \\
\text { standing position. These activities may occur with or without therapist assistance. }\end{array}$ \\
\hline Pre-gait & $\begin{array}{l}\text { Assisting the patient in exercises prior to ambulation, e.g. weight shifting from foot to foot, stepping in } \\
\text { place, and sideways stepping }\end{array}$ \\
\hline Ambulation & Gait training of the patient, with or without assistance by therapist or device (e.g. walker) \\
\hline Adverse sequelae & Definition/Description \\
\hline Joint contractures & $\begin{array}{l}\text { The diagnosis of a joint contracture will be according to a progress note by a clinician (MD, } \\
\text { physiotherapist or occupational therapist) stating that the "patient had a contracture" of any joint as } \\
\text { defined by a recorded range of motion that was short of the full range [31]. Only new onset } \\
\text { contractures will be noted. }\end{array}$ \\
\hline Pressure ulcer & $\begin{array}{l}\text { The diagnosis and location of a pressure ulcer will be according to a progress note by a clinician (MD, } \\
\text { registered nurse or physiotherapist) recording the development of "pressure ulcer", "pressure sore", } \\
\text { "skin necrosis", or "decubitus ulcer" that has developed as a result of pressure, shear or friction. Skin } \\
\text { ulceration attributable to other causes will not be included as a pressure ulcer. The classification of the } \\
\text { pressure ulcer will be done using the documentation in the patient chart [32]. }\end{array}$ \\
\hline $\begin{array}{l}\text { PCCU-acquired weakness } \\
\quad \text { (suspected or confirmed) }\end{array}$ & $\begin{array}{l}\text { The diagnosis of PCCU weakness will be according to a progress note or specialist consultation } \\
\text { recording the identification of any of the following on the current PCCU admission: } \\
\text { i) "Intensive care unit" or "PCCU acquired weakness", "critical illness polyneuropathy, myopathy, } \\
\text { or neuromuscular abnormality" } \\
\text { ii) muscle weakness } \\
\text { iii) decreased or absent deep tendon reflexes } \\
\text { iv) failure to liberate from mechanical ventilation } \\
\text { v) abnormal nerve conduction velocities and/or needle electromyography } \\
\text { vi) absence of definable or highly suspected etiology other than PCCU acquired weakness (essential } \\
\text { criteria) }\end{array}$ \\
\hline
\end{tabular}

$\mathrm{MD}=$ Medical doctor PCCU $=$ Pediatric critical care unit 


\section{References}

[1] Desai SV, Law TJ, Needham DM. Long-term complications of critical care. Crit Care Med 2011;39(2):371-9.

[2] Weinert CR, Calvin AD. Epidemiology of sedation and sedation adequacy for mechanically ventilated patients in a medical and surgical intensive care unit. Crit Care Med 2007;35(2): 393-401.

[3] Gosselink R, Bott J, Johnson M, Dean E, Nava S, Norrenberg M, et al. Physiotherapy for adult patients with critical illness: recommendations of the European Respiratory Society and European Society of Intensive Care Medicine Task Force on Physiotherapy for Critically Ill Patients. Intensive Care Med 2008;34(7): 1188-99.

[4] Needham DM, Wang W, Desai SV, Mendez-Tellez PA, Dennison CR, Sevransky J, et al. Intensive care unit exposures for long-term outcomes research: development and description of exposures for 150 patients with acute lung injury. J Crit Care 2007;22(4):275-84.

[5] Schweickert WD, Pohlman MC, Pohlman AS, Nigos C, Pawlik AJ, Esbrook CL, et al. Early physical and occupational therapy in mechanically ventilated, critically ill patients: a randomised controlled trial. Lancet 2009;373(9678):1874-82

[6] Banwell BL, Mildner RJ, Hassall AC, Becker LE, Vajsar J, Shemie SD. Muscle weakness in critically ill children. Neurology 2003;61(12):1779-82.

[7] Petersen B, Schneider C, Strassburg HM, Schrod L. Critical illness neuropathy in pediatric intensive care patients. Pediatr Neurol 1999;21(4):749-53.

[8] Pollack MM, Patel KM, Ruttimann UE. PRISM III: an updated Pediatric Risk of Mortality score. Crit Care Med 1996;24(5):743-52.

[9] Leteurtre S, Martinot A, Duhamel A, Proulx F, Grandbastien B, Cotting $\mathrm{J}$, et al. Validation of the paediatric logistic organ dysfunction (PELOD) score: prospective, observational, multicentre study. Lancet 2003;362(9379):192-7.

[10] Fiser DH, Long N, Roberson PK, Hefley G, Zolten K, Brodie-Fowler M. Relationship of pediatric overall performance category and pediatric cerebral performance category scores at pediatric intensive care unit discharge with outcome measures collected at hospital discharge and 1- and 6-month follow-up assessments. Crit Care Med 2000;28(7):2616-20.

[11] Hippocrates. On the articulations. The genuine works of Hippocrates. Clin Orthop Relat Res 2002;(400):19-25.

[12] Bednarík J, Vondracek P, Dusek L, Moravcova E, Cundrle I. Risk factors for critical illness polyneuromyopathy. J Neurol 2005;252(3):343-51.

[13] Herridge MS, Cheung AM, Tansey CM, Matte-Martyn A, Diaz-Granados N, Al-Saidi F, et al; Canadian Critical Care Trials Group. One-year outcomes in survivors of the acute respiratory distress syndrome. N Engl J Med 2003;348(8):683-93.

[14] Schweickert WD, Hall J. ICU-acquired weakness. Chest 2007; 131(5):1541-19.

[15] Burtin C, Clerckx B, Robbeets C, Ferdinande P, Langer D, Troosters $\mathrm{T}$, et al. Early exercise in critically ill patients enhances short-term functional recovery. Crit Care Med 2009;37(9):2499-505.
[16] Korupolu R, Gifford J, Needham D: Early Mobilization of Critically ill patients: Reducing Neuromuscular complications after Intensive Care. Contemp Crit Care 2009;6(9):1-12.

[17] Morris PE, Goad A, Thompson C, Taylor K, Harry B, Passmore L, et al. Early intensive care unit mobility therapy in the treatment of acute respiratory failure. Crit Care Med 2008;36(8):2238-43.

[18] Chaboyer W, Gass E, Foster M. Patterns of chest physiotherapy in Australian Intensive Care Units. J Crit Care 2004;19(3): 145-51.

[19] Norrenberg M, Vincent JL. A profile of European intensive care unit physiotherapists. European Society of Intensive Care Medicine. Intensive Care Med 2000;26(7):988-94.

[20] Stiller K. Physiotherapy in intensive care: towards an evidencebased practice. Chest 2000;118(6):1801-13.

[21] Hodgin KE, Nordon-Craft A, McFann KK, Mealer ML, Moss M. Physical therapy utilization in intensive care units: results from a national survey. Crit Care Med 2009;37(2):561-6.

[22] Cremer R, Leclerc F, Lacroix, Ploin D; GRUP/RMEF Chronic Diseases in PICU Study Group. Children with chronic conditions in pediatric intensive care units located in predominantly French-speaking regions: Prevalence and implications on rehabilitation care need and utilization. Crit Care Med 2009; 37(4):1456-62.

[23] Bailey P, Thomsen GE, Spuhler VJ, Blair R, Jewkes J, Bezdjian L, et al. Early activity is feasible and safe in respiratory failure patients. Crit Care Med 2007;35(1):139-45.

[24] Bourdin G, Barbier J, Burle JF, Durante G, Passant S, Vincent B, et al. Respir Care 2010;55(4):400-7.

[25] Fiser DH, Tilford JM, Roberson PK. Relationship of illness severity and length of stay to functional outcomes in the pediatric intensive care unit: a multi-institutional study. Crit Care Med 2000;28(4):1173-9.

[26] Hartman ME, McCrory DC, Schulman SR. Efficacy of sedation regimens to facilitate mechanical ventilation in the pediatric intensive care unit: a systematic review. Pediatr Crit Care Med 2009;10(2):246-55.

[27] Tobias JD. Tolerance, withdrawal, and physical dependency after long-term sedation and analgesia of children in the pediatric intensive care unit. Crit Care Med 2000;28(6):2122-32.

[28] Stevens RD, Dowdy DW, Michaels RK, Mendez-Tellez PA, Pronovost PJ, Needham DM. Neuromuscular dysfunction acquired in critical illness: a systematic review. Intensive Care Med 2007;33(11):1876-91.

[29] Hopkins RO. Does critical illness and intensive care unit treatment contribute to neurocognitive and functional morbidity in pediatric patients? J Pediatr (Rio J) 2007;83(6):488-90.

[30] Knoester H, Bronner MB, Bos AP. Surviving pediatric intensive care: physical outcome after 3 months. Intensive Care Med 2008;34(6):1076-82.

[31] Clavet H, Hébert PC, Fergusson D, Doucette S, Trudel G. Joint contracture following prolonged stay in the intensive care unit. CMAJ 2008;178(6):691-7.

[32] European pressure ulcer advisory panel and national pressure ulcer advisory panel. Treatment of pressure ulcers: Quick reference guide. Washington DC: National Pressure Ulcer Advisory Panel; 2009. 